\title{
STUDI PERUMUSAN STRATEGI PENGELOLAAN EKOWISATA BAHARI KOTA MANADO DI ERA REVOLUSI INDUSTRI 4.0 BERDASARKAN ANALISIS SWOT
}

\author{
(Study on the Formulation of Strategies for Managing Marine Ecotourism in the \\ Industrial Revolution 4.0 Era Based on SWOT Analysis)
}

\section{Sarif Hidayat, Antonius P. Rumengan, Suria Darwisito, Medy Ompi, Winda M. Mingkid, Billy Th. Wagey, Carolus P. Paruntu}

Program Studi IImu Kelautan, Fakultas Perikanan dan IImu Kelautan, Unsrat, Manado, 95115. *corresponding author: carolusparuntu@yahoo.com

The objective of this research was to formulate a strategy for managing maritime ecotourism in the era of industrial revolution 4.0 in the city of Manado. The study was conducted at the coastal areas of the mainland of Manado City and Bunaken Island for 3 months, February - May 2019. The research method was a survey with descriptive analysis and SWOT. The results of the study obtained 4 strategy formulations (key success factors) in the context of managing maritime ecotourism in the industrial revolution era 4.0 in the city of Manado, namely: 1) Increasing law enforcement in the field of marine ecotourism, waste management on land and sea, 2) Awareness of the community environmental hygiene both on land and sea, 3) Empowering biodiversity resources of coral reefs, seagrass beds and mangroves in the park for developing marine maritime ecotourism through digital applications, and 4) managing and developing resorts, coastal culinary attractions, points of diving spots, and tourism ports. The results of the SWOT curve show the condition of marine ecotourism in the city of Manado in quadrant 2, namely a situation where the threat to the development of marine ecotourism is more dominant than opportunity, but there are strengths of tourism organizations that can be relied on. Stakeholders are expected to be able to improve performance so that quadrant 2 conditions change to quadrant 1 , which is to support an aggressive strategy: a very good situation because of the power that is used to seize profitable opportunities. In the era of industrial revolution 4.0, every stakeholder in the maritime ecotourism industry in the city of Manado was supposed to change the management system towards digital-based by making applications

Keywords: Bunaken island, revolution industry 4.0, Manado city, marine ecotourism, strategy

Tujuan penelitian adalah untuk merumuskan strategi pengelolaan ekowisata bahari di era revolusi industri 4.0 di Kota Manado. Penelitian dilakukan di wilayah pesisir daratan Kota Manado dan Pulau Bunaken selama 3 bulan, Februari - Mei 2019. Metode penelitian adalah survei dengan analisis deskriptif dan SWOT. Hasil penelitian diperoleh 4 rumusan strategi (faktor-faktor kunci keberhasilan) dalam rangka pengelolaan ekowisata bahari era revolusi industri 4.0 di Kota Manado, yaitu: 1) Meningkatkan penegakan hukum di bidang ekowisata bahari, pengelolaan sampah di darat maupun laut, 2) Menyadarkan masyarakat tentang kebersihan lingkungan baik di daratan maupun lautan, 3) Memberdayakan sumber daya keanekaragaman hayati terumbu karang, padang lamun dan mangrove di kawasan TNB untuk pengembangan ekowisata bahari melalui aplikasi digital, dan 4) Mengelola dan mengembangkan resort, tempat-tempat wisata kuliner pantai, titik-titik penyelaman, dan pelabuhan pariwisata. Hasil kurva SWOT memperlihatkan kondisi ekowisata bahari Kota Manado berada dalam kuadran 2, yaitu situasi dimana ancaman terhadap pengembangan ekowisata bahari lebih dominan dibandingkan peluang, namun ada kekuatan organisasi kepariwisataan yang dapat diandalkan. Pemangku kepentingan diharapkan dapat meningkatkan kinerja agar kondisi kuadran 2 berubah menjadi kuadran 1, yaitu mendukung strategi agresif: situasi yang sangat baik karena adanya kekuatan yang dimanfaatkan untuk meraih peluang yang menguntungkan. Dalam era revolusi industri 4.0, maka setiap pemangku kepentingan industri ekowisata bahari di Kota Manado sudah seharusnya merubah sistem pengelolaan yang ada ke arah berbasis digital dengan cara membuat aplikasi pengelolaan ekowisata bahari.

Kata Kunci: Ekowisata bahari, revolusi industri 4.0, Kota Manado, Pulau Bunaken, strategi 


\section{PENDAHULUAN}

Sektor pariwisata semakin penting seiring dengan perkembangan struktur ekonomi Indonesia yang mengarah ke sektor jasa (Bagindo dkk., 2016). Ekowisata bahari merupakan salah satu jenis ekowisata menurut Peraturan Menteri Dalam Negeri No. 33 Tahun 2009 tentang pedoman pengembangan ekowisata di daerah. Kehadiran era revolusi industri 4.0 sudah tidak dapat dielakkan lagi, sehingga Indonesia perlu mempersiapkan langkah-langkah strategis agar mampu beradaptasi dengan era revolusi industri 4.0 berbasis digital (Satya, 2018), maka dari latar belakang di atas didapatkan rumusan masalah bagaimana merumuskan strategi pengelolaan ekowisata bahari era revolusi industri 4.0 di Kota Manado.

\section{METODE PENELITIAN}

\section{Waktu dan Tempat}

Waktu penelitian ini adalah selama 3 bulan (Februari - Mei 2019). Tempat penelitian adalah wilayah pesisir daratan Kota Manado dan Pulau Bunaken.
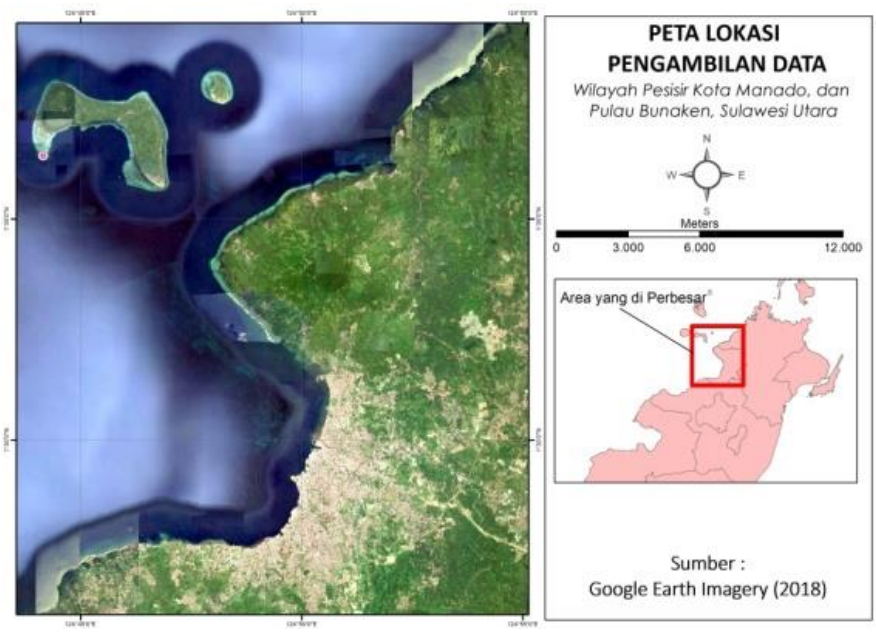

Gambar 1. Peta Kota Manado.

\section{Alat dan Bahan}

Alat dan bahan yang digunakan dalam penelitian ini adalah kamera, alat tulis menulis, dan kuisioner. Alat dan bahan penunjang lainnya, yaitu sepeda motor, komputer, printer, handphone, microsoft word dan microsoft exel.

\section{Pengumpulan Data}

Metode penelitian yang digunakan adalah survei dan di analisis deskriptif berdasarkan Martono (2010). Jenis data yang dikumpulkan berupa data primer dan data sekunder. Data primer diperoleh langsung di lokasi penelitian melalui wawancara dan observasi terencana (menggunakan kuisioner) terhadap industri pariwisata seperti resort, tempat-tempat wisata kuliner pantai dan ekowisata bahari mangrove, sedangkan pengumpulan data sekunder melalui internet, penelusuran kepustakaan dari buku, jurnal, laporan dan dokumen dari instansi terkait.

\section{Analisis Data}

Data yang didapatkan dianalisis menggunakan SWOT berpedoman pada Rangkuti (2015), Bahagia dkk. (2016), dan Paruntu dan Rumengan (2018). Pentahapan analisis SWOT, yaitu: 1) Menetapkan visi, misi, dan nilai kepemimpinan Kota Manado yang berlaku sekarang ini, 2) Pencermatan 
lingkungan internal (PLI) dan eksternal (PLE), 3) Kesimpulan analisis faktor internal (KAFI) dan eksternal (KAFE), 4) Membuat matriks analisis SWOT dengan mengkomibinasikan antara kekuatan dan kelemahan utama versus peluang dan ancaman utama untuk memperoleh asumsi-asumsi strategi, 5) Penetapan urutan asumsi-asumsi strategi prioritas (yaitu minimal 3 (tiga) dan maksimal 7 (tujuh) urutan) untuk mencapai faktor-faktor kunci keberhasilan (FKK) dalam rangka membangun ekowisata bahari Kota Manado di era revolusi industri 4.0.

\section{HASIL DAN PEMBAHASAN}

\section{Visi dan Misi Kota Manado Tahun 2016 - 2021}

Visi: "Manado Pariwisata Dunia".

Misi:

1. Mewujudkan pemerintahan pelayanan yang baik, bersih serta demokratis, yang berorientasi kepariwisataan;

2. Mewujudkan masyarakat Kota Manado berdaya saing yang mendukung kepariwisataan; dan

3. Mewujudkan lingkungan asri dan lestari yang menopang kepariwisataan.

Nilai:

1. Organizational
Berperilaku secara organizational yakni berinteraksi satu sama lain dalam memecahkan masalah.

2 Inovatif

Menjaga dan melanjutkan tradisi inovasi serta ingin melakukan perubahan sesuai tantangan

3. Responsive

Mengenali harapan masyarakat dan memenuhi janji secara tepat waktu, menunjukan rasa hormat kepada semua bawahan, memberikan komitmen dan mendorong partisipasi bawahan dalam pelayanan masyarakat.

\section{SWOT}

Pencermatan lingkungan internal (PLI) dan pencermatan lingkungan eksternal (PLE)

Lembaga pemerintah Kota Manado hidup dalam suatu sistem selalu saling berhubungan dan mempengaruhi. Dalam rangka merumuskan strategi pengelolaan ekowisata bahari Kota Manado di era revolusi industry 4.0, maka perlu dilakukan pencermatan lingkungan internal untuk mengetahui kekuatan dan kelemahan internal organisasi Kota Manado dan pencermatan lingkungan eksternal untuk mengetahui peluang dan ancaman eksternal terhadap organisasi Kota Manado. Pencermatan lingkungan internal dan eksternal dapat dilihat pada Tabel 1.

Tabel 1. Pencermatan lingkungan internal dan eksternal (PLI dan PLE)

\begin{tabular}{|c|c|c|}
\hline & Kekuatan (Strengths) & Kelemahan (Weakness) \\
\hline $\mathbf{P}$ & $\begin{array}{l}\text { 1. Kota Manado } \\
\text { memiliki resort, } \\
\text { tempat-tempat wisata kuliner }\end{array}$ & $\begin{array}{l}\text { 1. Kurangnya kesadaran masyarakat } \\
\text { tentang kebersihan lingkungan } \\
\text { yang mengakibatkan banyaknya }\end{array}$ \\
\hline $\mathbf{L}$ & $\begin{array}{l}\text { pantai, titik-titik penyelaman, } \\
\text { pelabuhan pariwisata, lokasi }\end{array}$ & $\begin{array}{l}\text { sampah di pesisir pantai Kota } \\
\text { Manado dan Pulau Bunaken. }\end{array}$ \\
\hline I & $\begin{array}{l}\text { ekowisata mangrove yang } \\
\text { dikelola. } \\
\text { 2. Kota Manado memiliki Pulau }\end{array}$ & $\begin{array}{l}\text { 2. Kurangnya air tawar bersih di } \\
\text { Pulau Bunaken. } \\
\text { 3. Penegakan hukum tentang }\end{array}$ \\
\hline
\end{tabular}




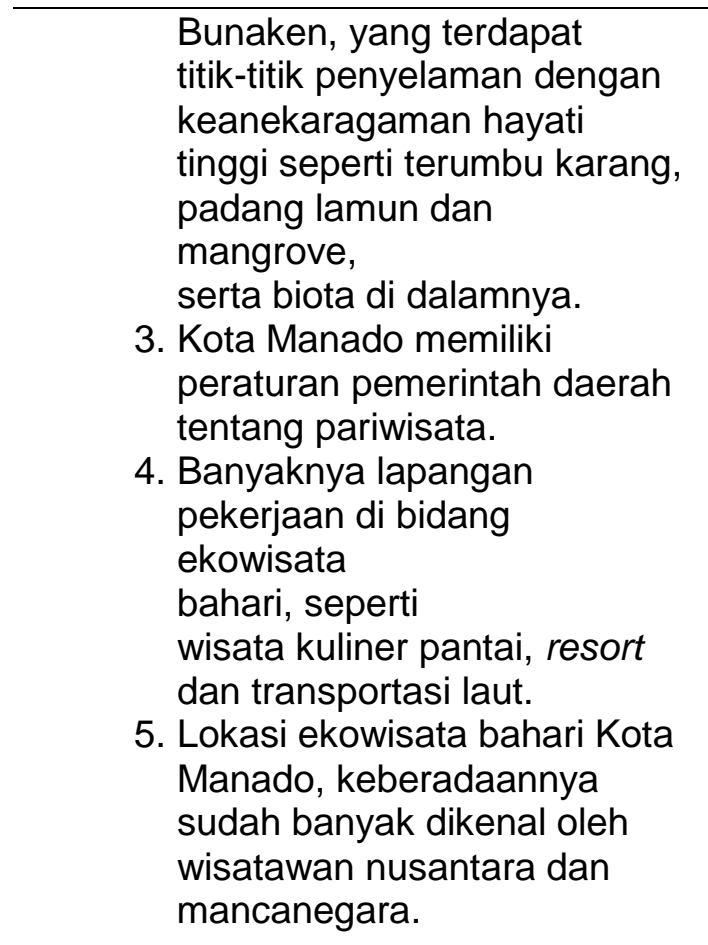

ekowisata bahari masih lemah.

4. Banyak pemandu wisatawan yang tidak melaksanakan Standar Oprasional Prosedur.

5. Sarana dan prasarana pendukung ekowisata bahari Kota Manado kurang memadai.

\begin{tabular}{|c|c|c|}
\hline & Peluang (Opportunities) & Ancaman (Threats) \\
\hline $\mathbf{P}$ & $\begin{array}{l}\text { 1. Banyaknya wisatawan } \\
\text { mancanegara dan nusantara } \\
\text { yang berwisata di Pulau }\end{array}$ & $\begin{array}{l}\text { 1. Persaingan harga pasar dengan } \\
\text { negara lain di bidang ekowisata } \\
\text { bahari. }\end{array}$ \\
\hline $\mathbf{L}$ & $\begin{array}{l}\text { Bunaken dan sekitarnya } \\
\text { setiap tahun. }\end{array}$ & $\begin{array}{l}\text { 2. Menurunnya daya dukung } \\
\text { lingkungan akibat kurangnya }\end{array}$ \\
\hline $\mathbf{E}$ & $\begin{array}{l}\text { 2. Pariwisata Kota Manado } \\
\text { menghadapi era revolusi } \\
\text { industri } 4.0 \\
\text { 3. Adanya organisasi CTI (Coral } \\
\text { Triangel initiative) yang } \\
\text { berpusat di Kota Manado } \\
\text { sehubungan dengan } \\
\text { pelestarian terumbu karang. } \\
\text { 4. Adanya profesi tenaga } \\
\text { pariwisata MEA. } \\
\text { 5. Banyaknya program } \\
\text { kepariwisataan dikementerian } \\
\text { pariwisata. }\end{array}$ & $\begin{array}{l}\text { pemahaman wisatawan akan } \\
\text { kelestarian lingkungan. } \\
\text { 3. Adanya ancaman bencana alam } \\
\text { yang biasanya terjadi ketika } \\
\text { musim angin barat pada bulan } \\
\text { Oktober sampai bulan April di } \\
\text { Kota Manado } \\
\text { 4. Adanya lokasi ekowisata bahari di } \\
\text { tempat lain yang menawarkan } \\
\text { fasilitas menarik dibanding } \\
\text { ekowisata bahari di pantai } \\
\text { Kota Manado dan Pulau Bunaken. } \\
\text { 5. Banyaknya sampah plastik masuk } \\
\text { ke perairan yang mengancam } \\
\text { wilayah pesisir Kota Manado dan } \\
\text { Pulau Bunaken. }\end{array}$ \\
\hline
\end{tabular}

Dari pencermatan lingkungan internal dan eksternal tersebut dapat dibuat pembobotan untuk mencapai faktor- faktor utama yang sangat berpengaruh terhadap pembangunan ekowisata bahari Kota Manado (Tabel 2). 
Tabel 2. Kesimpulan analisis faktor internal (KAFI) dan kesimpulan analisis faktor eksternal (KAFE)

\begin{tabular}{llcc}
\hline LINGKUNGAN & BOBOT RATING $\begin{array}{c}\text { SCORE } \\
\text { (Bobot } x \\
\text { Rating) }\end{array}$ & $\begin{array}{c}\text { PRIORI } \\
\text { TAS }\end{array}$ \\
\hline
\end{tabular}

\section{KEKUATAN:}

1. Kota Manado memiliki resort, tempattempat wisata kuliner pantai, titik-titik

penyelaman, pelabuhan pariwisata, lokasi ekowisata mangrove yang dikelalo.

2. Kota Manado memiliki Pulau Bunaken, yang terdapat titik-titik penyelaman dengan keanekaragaman hayati tinggi seperti terumbu karang, padang lamun dan mangrove serta biota di dalamnya.

3. Kota Manado memiliki peraturan pemerintah daerah tentang pariwisata.

4. Banyaknya lapangan pekerjaan di bidang ekowisata bahari, seperti wisata

$5 \quad 4 \quad 20$
kuliner pantai, resort dan transportasi laut.

5. Lokasi ekowisata bahari Kota Manado, keberadaannya sudah banyak dikenal

$\begin{array}{lll}4 & 4 & 16\end{array}$
oleh wisatawan nusantara dan mancanegara.

\section{KELEMAHAN:}

1. Kurangnya kesadaran masyarakat 14 4 56 II Tentang kebersihan lingkungan yang mengakibatkan banyaknya sampah di pesisir pantai Kota Manado.

2. Kurangnya air tawar bersih di Pulau Bunaken.

$\begin{array}{lll}8 & 4 & 32\end{array}$

3. Penegakan hukum tentang ekowisata bahari masih lemah.

4. Banyak pemandu wisatawan yang tidak melaksanakan standar oprasional prosedur.

5. Sarana dan prasarana pendukung ekowisata bahari Kota Manado kurang memadai.

$\begin{array}{lll}5 & 3 & 15\end{array}$




\begin{tabular}{|c|c|c|c|c|}
\hline LINGKUNGAN & ВOBOT & RATING & $\begin{array}{c}\text { SCORE } \\
\text { (Bobot } x \\
\text { Rating) }\end{array}$ & $\begin{array}{c}\text { PRIORI } \\
\text { TAS }\end{array}$ \\
\hline
\end{tabular}

\section{PELUANG:}

1. Banyaknya wisatawan mancanegara dan nusantara yang berwisata di Pulau Bunaken dan sekitarnya setiap tahun.

2. Pariwisata Kota Manado menghadapi era revolusi industri 4.0

3. Adanya organisasi CTI yang berpusat di Kota Manado sehubungan dengan pelestarian terumbu karang.

4. Adanya profesi tenaga pariwisata MEA.
5

12

15
4

4

4

4

4

4

36

16

7

4

28

biasanya terjadi ketika musim angin barat pada bulan Oktober sampai bulan April di Kota Manado.

4. Adanya lokasi ekowisata bahari di tempat lain yang menawarkan fasilitas menarik dibandingkan ekowisata bahari di Kota Manado.

5. Banyaknya sampah plastik masuk ke perairan yang mengancam wilayah pesisir Kota Manado dan Pulau Bunaken
Keterangan:

1. "Bobot" pada masing-masing faktor berdasarkan dampak yang mungkin ditimbulkannya pada keberhasilan pembangunan ekowisata bahari Kota Manado masa kini dan masa depan. Keseluruhan bobot berjumlah 100.
2. "Rating" bagi setiap faktor mulai dari 4 (sangat menonjol), sampai dengan 1 (paling tidak menonjol) berdasarkan respons organisasi terhadap faktor tersebut.

3. "Skor" dengan mengalikan bobot dengan rating. 
4. Kesimpulan dengan memberikan urutan prioritas pada kekuatan, kelemahan, peluang dan ancaman.

Nilai keterkaitan: $1=$ tidak terkait, $2=$ cukup terkait, $3=$ terkait, dan $4=$ sangat terkait.

Dari Tabel 2 di atas, maka Kesimpulan analisis faktor internal (KAFI) dan analisis faktor eksternal (KAFE), ditetapkan 2 (dua) dari masing-masing faktor sebagai berikut:

\section{Kekuatan Utama:}

1. Kota Manado memiliki Pulau Bunaken, yang terdapat titik-titik penyelaman dengan keanekaragaman hayati tinggi seperti terumbu karang, padang lamun dan mangrove serta biota di dalamnya.

2. Kota Manado memiliki resort pantai, wisata kuliner pantai pelabuhan pariwisata, lokasi ekowisata mangrove yang dikelalo.

\section{Kelemahan Utama:}

1. Penegakan hukum yang masih lemah.

2. Kurangnya kesadaran masyarakat tentang kebersihan lingkungan yang mengakibatkan banyaknya sampah di pesisir pantai Kota Manado.

\section{Peluang Utama:}

1. Adanya organisasi CTI yang berpusat di Kota Manado sehubungan dengan pelestarian terumbu karang.

2. Pariwisata Kota Manado menghadapi era industri 4.0

\section{Ancaman Utama:}

1. Menurunnya lingkungan

$\begin{array}{cr}\text { daya } & \begin{array}{r}\text { dukung } \\ \text { kurangnya }\end{array} \\ \text { akibat } & \text { kurang }\end{array}$

pemahaman wisatawan akan kelestarian lingkungan.

2. Banyaknya sampah plastik masuk ke perairan yang mengancam ekowisata bahari Kota Manado.

\section{Kondisi Ekowisata Bahari Kota Manado}

Berdasarkan analisis SWOT kondisi ekowisata bahari Kota Manado menunjukkan bahwa dalam operasionalnya memiliki kekuatan yang lebih dominan dibandingkan kelemahan, namun peluang yang lebih kecil dibandingkan ancamannya. Hasil analisis SWOT, disajikan sebagai berikut:

Nilai Kekuatan - Nilai Kelemahan $=196$ $-190=6$

Nilai Peluang - Nilai Ancaman $=188-$ $212=-24$

Hasil perhitungan melalui Tabel 2 di atas, maka skor yang ditampilkan dapat ditelusuri beberapa alternatif pengelolaan ekowisata bahari melalui pilihan strategi dalam kurva SWOT, yaitu:

a. pada faktor internal, selisih skor kekuatan (S) dan kelemahan (W) memperlihatkan bahwa $\mathrm{x}>0$ (Positiff), dengan selisih skor $S$ W sebesar 6;

b. Selanjutnya pada faktor eksternal, selisih skor peluang (O) dengan ancaman (T) memperlihatkan bahwa $y<0$ (negative), dengan selisih skor O-T sebesar - 24 .

Dengan demikian nilai tersebut dapat dipetakan dalam empat kuadran kurva SWOT di bawah ini (Gambar 2 dan Tabel 3) 


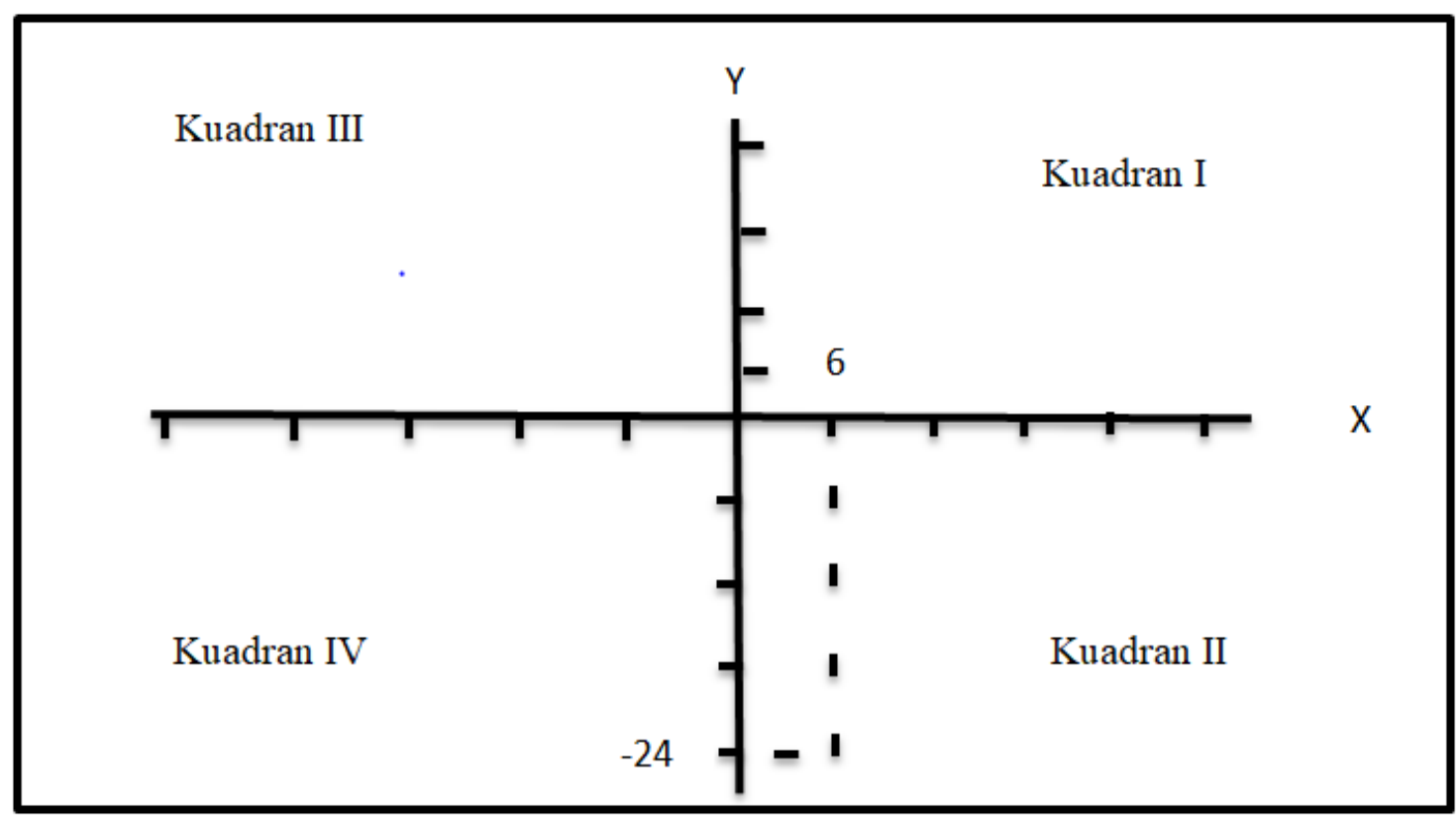

Gambar 2. Posisi ekowisata bahari di Kota Manado berdasarkan analisis dan kurva SWOT.

Hasil dari kuadran kurva menunjukkan bahwa kondisi ekowisata bahari Kota Manado berada dalam kuadran 2, yaitu mendukung strategi inovasi atau strategi diversifikasi: situasi bahwa meskipun kondisi ekowisata bahari Kota Manado menghadapi ancaman, namun ada kekuatan yang dapat diandalkan (Tabel 3). Berdasarkan hasil kurva SWOT yang diperlihatkan pada Gambar 2 di atas, maka disarankan kepada para pengelola atau pengambil kebijakan (pemerintah) di sektor kepariwisataan agar meningkatkan kinerja dengan memanfaatkan kekuatan internal organisasi kepariwisataan, terlebih khusus di bidang ekowisata bahari untuk meraih peluang yang menguntungkan dan memperkecil ancaman, sehingga kondisi ekowisata bahari Kota Manado dapat ditingkatkan dari kondisi kuadran 2 menjadi kuadran 1 seperti yang di jelaskan dalam Tabel 3. Penjelasan kurva SWOT mengacu pada Rangkuti (2006), dan Sutanto dkk. (2016), Posundu dkk. (2019).

Tabel 3. Strategi dari masing-masing daerah Kurva SWOT

\begin{tabular}{|c|c|}
\hline $\begin{array}{c}\text { Kuadran III } \\
\text { Mendukung kondisi konsulidasi, } \\
\text { perbaikan, mengubah cara pandang } \\
\text { serta menghilangkan penyebab } \\
\text { masalah agar ancaman dapat } \\
\text { dihindari: organisasi mengalami } \\
\text { kelemahan dalam berbagai hal } \\
\text { (internal), sehingga peluang yang } \\
\text { menguntungkan sulit dicapai. }\end{array}$ & $\begin{array}{c}\text { Kuadran I } \\
\text { Mendukung Strategi Agresif: } \\
\text { Situasi yang sangat baik karena } \\
\text { adanya kekuatan yang dimanfaatkan } \\
\text { untuk meraih peluang yang } \\
\text { menguntungkan. }\end{array}$ \\
\hline $\begin{array}{c}\text { Kuadran IV } \\
\text { Mendukung Strategi Defensif } \\
\text { misalnya perampingan, } \\
\text { pengurangan atau efisiensi dalam } \\
\text { semua bidang kegiatan: situasi }\end{array}$ & $\begin{array}{c}\text { Kuadran II } \\
\text { Mendukung Strategi Inovasi atau } \\
\text { strategi diversifikasi: Situasi bahwa } \\
\text { meskipun organisasi menghadapi } \\
\text { ancaman namun ada kekuatan yang }\end{array}$ \\
\hline
\end{tabular}




\begin{tabular}{cc}
\hline organisasi sangat buruk karena di & dapat diandalkan \\
samping berbagai kelemahan internal & \\
timbul ancaman dari luar. & \\
\hline
\end{tabular}

Setelah hasil KAFI dan KAFE, maka diperoleh hasil asumsi-asumsi strategi

melalui analisis matriks SWOT (Tabel 4).

Tabel 4. Matriks Analisis SWOT

\begin{tabular}{|c|c|c|}
\hline & KEKUATAN (S) & KELEMAHAN (W) \\
\hline KAFE & $\begin{array}{l}\text { 1. Kota Manado } \\
\text { Memiliki TNB yang } \\
\text { terdapat titik-titik } \\
\text { penyelaman } \\
\text { dengan } \\
\text { keanekaragaman } \\
\text { hayati tinggi seperti } \\
\text { terumbu karang, } \\
\text { padang lamun dan } \\
\text { mangrove serta } \\
\text { biota di dalamnya. } \\
\\
\text { 2. Kota Manado secara } \\
\text { resmi memiliki } \\
\text { resort, tempat- } \\
\text { tempat wisata } \\
\text { kuliner pantai, titik-titik } \\
\text { penyelaman,pelabuhan } \\
\text { pariwisata, lokasi } \\
\text { ekowisata mangrove } \\
\text { yang dikelalo. }\end{array}$ & $\begin{array}{l}\text { 1. Penegakan hukum } \\
\text { tentang ekowisata } \\
\text { bahari masih lemah. } \\
\text { 2. Kurangnya } \\
\text { kesadaran } \\
\text { masyarakat tentang } \\
\text { kebersihan } \\
\text { lingkungan yang } \\
\text { mengakibatkan } \\
\text { banyaknya sampah } \\
\text { di pesisir pantai Kota } \\
\text { Manado dan Pulau } \\
\text { Bunaken. }\end{array}$ \\
\hline PELUANG (0) & Strategi (SO) & Strategi (WO) \\
\hline $\begin{array}{l}\text { 1. Adanya } \\
\text { organisasi CTI } \\
\text { yang berpusat di } \\
\text { Kota Manado } \\
\text { sehubungan } \\
\text { dengan } \\
\text { pelestarian } \\
\text { terumbu karang. }\end{array}$ & $\begin{array}{l}\text { 1.1 Memanfaatkan } \\
\text { keanekaragaman } \\
\text { hayati terumbu karang } \\
\text { TNB sebagai } \\
\text { program utama dari } \\
\text { organisasi CTI untuk } \\
\text { pelestarian lingkungan } \\
\text { hidup dan ekowisata } \\
\text { bahari. }\end{array}$ & $\begin{array}{l}\text { 1.1 Memperkuat } \\
\text { penegakan hukum di } \\
\text { bidang } \\
\text { kepariwisataan } \\
\text { (ekowisata bahari) } \\
\text { untuk mendukung } \\
\text { program CTI dalam } \\
\text { pelestarian terumbu } \\
\text { karang. }\end{array}$ \\
\hline $\begin{array}{l}\text { 2. Pariwisata Kota } \\
\text { Manado } \\
\text { menghadapi era } \\
\text { revolusi industri } \\
4.0\end{array}$ & $\begin{array}{l}\text { 1.2 Memanfaatkan } \\
\text { keanekaragaman } \\
\text { hayati terumbu karang } \\
\text { TNB untuk } \\
\text { dipromosikan } \\
\text { melalui aplikasi } \\
\text { digital dalam rangka } \\
\text { menghadapi era } \\
\text { revolusi industri } 4.0\end{array}$ & $\begin{array}{l}\text { 1.2 Memperkuat } \\
\text { penegakan hukum di } \\
\text { bidang } \\
\text { kepariwisataan } \\
\text { (ekowisata bahari) } \\
\text { untuk menghadapi } \\
\text { era revolusi industri } \\
4.0 \text {. } \\
\text { 2.1 Meningkatkan }\end{array}$ \\
\hline
\end{tabular}




\begin{tabular}{|c|c|c|}
\hline & $\begin{array}{l}\text { 2.1 Memanfaatkan } \\
\text { sarana resort pantai, } \\
\text { tempat-tempat } \\
\text { wisata kuliner } \\
\text { pantai, titik-titik } \\
\text { penyelaman, } \\
\text { pelabuhan } \\
\text { pariwisata, lokasi } \\
\text { ekowisata mangrove } \\
\text { untuk menunjang } \\
\text { program CTI } \\
\text { mengenai } \\
\text { pelestarian terumbu } \\
\text { karang dan ekowisata } \\
\text { bahari. } \\
\\
\text { 2.2 Mengelola } \\
\text { sarana resort pantai, } \\
\text { tempat-tempat } \\
\text { wisata kuliner } \\
\text { pantai, titik-titik } \\
\text { penyelaman, } \\
\text { pelabuhan } \\
\text { pariwisata, lokasi } \\
\text { ekowisata mangrove } \\
\text { untuk menunjang } \\
\text { ekowisata bahari Kota } \\
\text { Manado berbasis } \\
\text { digital era industri } 4.0 .\end{array}$ & $\begin{array}{l}\text { kesadaran } \\
\text { masyarakat } \\
\text { tentang kebersihan } \\
\text { lingkungan sehingga } \\
\text { dapat membantu } \\
\text { program organisasi } \\
\text { CTI dalam proses } \\
\text { pelestarian terumbu } \\
\text { karang. } \\
\text { 2.2 Meningkatkan } \\
\text { kesadaran } \\
\text { masyarakat } \\
\text { tentang kebersihan } \\
\text { lingkungan, sehingga } \\
\text { mendorong } \\
\text { ekowisata } \\
\text { bahari Kota Manado } \\
\text { dapat bersaing } \\
\text { dalam menghadapi } \\
\text { era revolusi } \\
\text { industri 4.0. }\end{array}$ \\
\hline ANCAMAN (T) & Strategi (ST) & Strategi (WT) \\
\hline $\begin{array}{l}\text { 1. Menurunnya } \\
\text { daya dukung } \\
\text { lingkungan } \\
\text { akibat } \\
\text { kurangnya } \\
\text { pemahaman } \\
\text { wisatawan akan } \\
\text { kelestarian } \\
\text { lingkungan. } \\
\text { 2. Banyaknya }\end{array}$ & $\begin{array}{l}\text { 1.1 Meningkatkan } \\
\text { pelestarian } \\
\text { keanekaragaman } \\
\text { hayati terumbu karang } \\
\text { TNB dengan } \\
\text { meminimalisir } \\
\text { menurunya daya } \\
\text { dukung lingkungan } \\
\text { yang diakibatkan } \\
\text { oleh wisatawan yang } \\
\text { tidak melakukan SOP. }\end{array}$ & $\begin{array}{l}\text { 1.1 Melaksanakan } \\
\text { penegakan hukum } \\
\text { terhadap wisatawan } \\
\text { yang melanggar } \\
\text { peraturan dalam } \\
\text { rangka } \\
\text { meminimalisir } \\
\text { kerusakan } \\
\text { lingkungan } \\
\text { ekowisata bahari } \\
\text { Kota Manado }\end{array}$ \\
\hline $\begin{array}{l}\text { masuk ke } \\
\text { perairan yang } \\
\text { mengancam } \\
\text { wilayah pesisir } \\
\text { Kota Manado } \\
\text { dan pulau } \\
\text { bunaken. }\end{array}$ & $\begin{array}{l}\text { 1.2 Menjaga kelestarian } \\
\text { TNB dengan } \\
\text { meminimalisir } \\
\text { sampah laut (marine } \\
\text { debris). } \\
\\
\text { 2.1 Meningkatkan } \\
\text { kualitas sumber } \\
\text { daya manusia }\end{array}$ & $\begin{array}{l}\text { 1.2 Melaksanakan } \\
\text { penegakan hukum } \\
\text { terhadap } \\
\text { pengelolaan } \\
\text { sampah di darat } \\
\text { maupun di laut } \\
\text { dalam rangka } \\
\text { pembangunan } \\
\text { ekowisata bahari }\end{array}$ \\
\hline
\end{tabular}




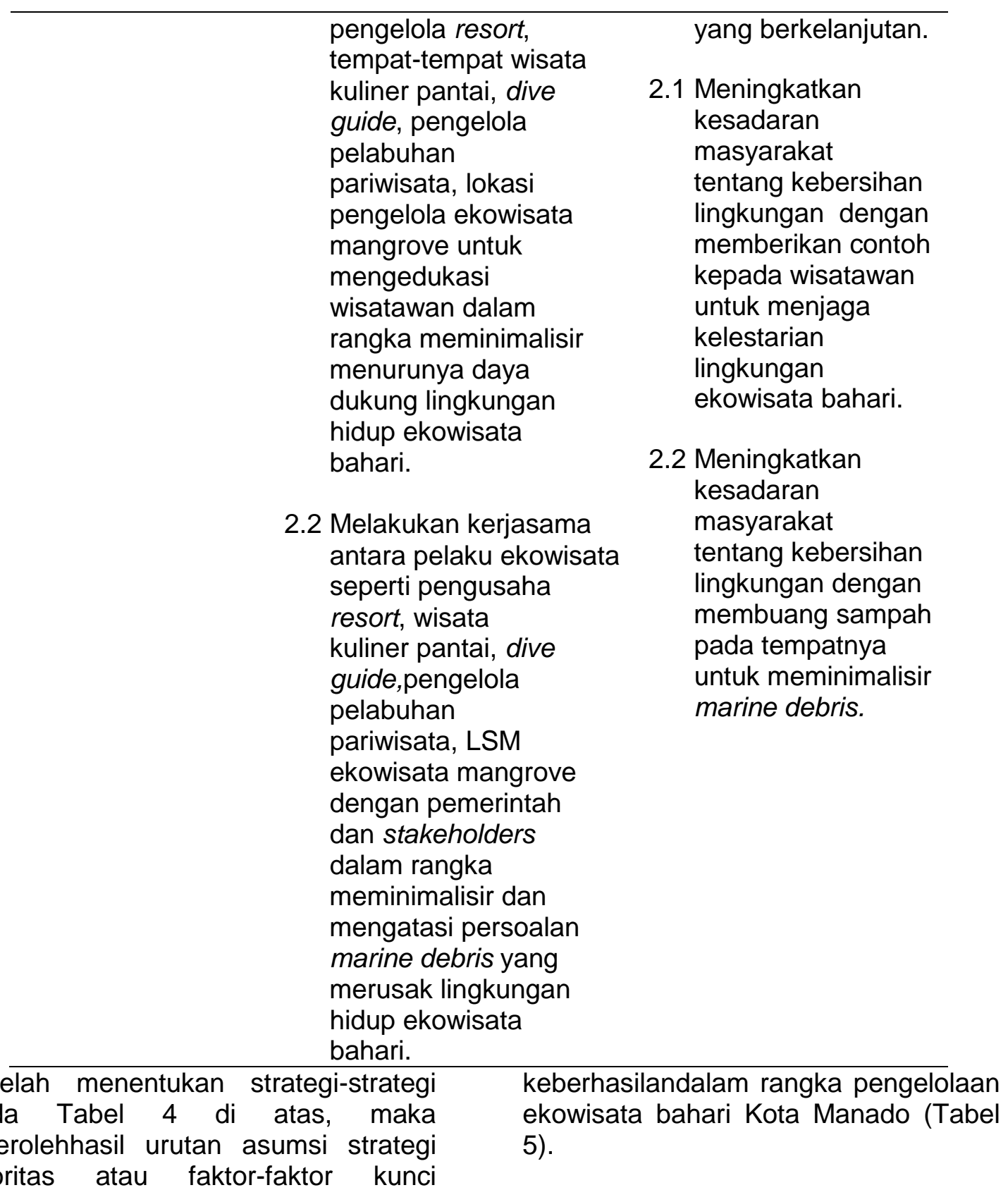

Tabel 5. Penetapan urutan asumsi strategi pilihan untuk mencapai $F K K$

\begin{tabular}{|c|c|c|c|c|}
\hline \multirow{3}{*}{ ASUMSI STRATEGI } & \multicolumn{3}{|c|}{$\begin{array}{l}\text { KETERKAITAN } \\
\text { DENGAN }\end{array}$} & \multirow{3}{*}{$\begin{array}{l}\text { URUTAN } \\
\text { PILIHAN } \\
\text { ASUMSI }\end{array}$} \\
\hline & \multirow{2}{*}{ VISI } & MISI & $\begin{array}{l}\text { NILAI- } \\
\text { NILAI }\end{array}$ & \\
\hline & & 123 & 123 & \\
\hline \multicolumn{5}{|l|}{ A. STRATEGI (SO) } \\
\hline $\begin{array}{l}\text { 1.1 Memanfaatkan keanekaragaman } \\
\text { hayati terumbu karang TNB } \\
\text { sebagai program utama dari } \\
\text { organisasi CTI untuk pelestarian } \\
\text { lingkungan hidup dan ekowisata }\end{array}$ & 4 & 224 & 242 & 20 \\
\hline
\end{tabular}


bahari.

1.2 Memanfaatkan keanekaragaman hayati terumbu karang TNB untuk $\begin{array}{llllllll}4 & 3 & 3 & 4 & 2 & 4 & 4 & 24 \\ (\mathrm{~V})\end{array}$ dipromosikan melalui aplikasi digital dalam rangka menghadapi era revolusi industri 4.0

2.1 Memanfaatkan sarana resort, tempat-tempat wisata kuliner pantai, titik-titik penyelaman, pelabuhan pariwisata, lokasi ekowisata mangrove untuk menunjang program CTI mengenai pelestarian terumbu karang dan ekowisata bahari.

2.2 Mengelola sarana resort, tempat-tempat wisata kuliner pantai, titik-titik penyelaman, pelabuhan pariwisata, lokasi ekowisata mangrove untuk menunjang ekowisata bahari Kota Manado berbasis digital era Revolusi industri 4.0.

\section{B. STRATEGI (ST)}

1.1 Meningkatkan pelestarian keanekaragaman hayati terumbu karang TNB dengan meminimalisir menurunya daya dukung lingkungan yang diakibatkan oleh wisatawan yang tidak melakukan SOP.

1.2 Menjaga kelestarian TNB dengan Meminimalisir sampah laut (marine debris).

2.1 Meningkatkan kualitas sumber daya manusia pengelola resort pantai, tempat-tempat wisata kuliner pantai, dive guide, pengelola pelabuhan pariwisata, lokasi pengelola ekowisata mangrove untuk mengedukasi wisatawan dalam rangka meminimalisir menurunya daya dukung lingkungan hidup ekowisata bahari. 
pengusaha resort, wisata

kuliner pantai, dive guide, pengelola pelabuhan pariwisata, LSM ekowisata mangrove dengan pemerintah dan stakeholder dalam rangka meminimalisir dan mengatasi persoalan marine debris yang merusak lingkungan hidup ekowisata bahari.

\section{STRATEGI (WO)}

1.1 Memperkuat penegakan hukum di bidang kepariwisataan (ekowisata $\begin{array}{llllllll}4 & 2 & 3 & 4 & 3 & 3 & 3 & 22\end{array}$ bahari untuk mendukung program CTI dalam pelestarian terumbu karang.

1.2 Memperkuat penegakan hukum di bidang kepariwisataan (ekowisata bahari) untuk menghadapi era revolusi industri 4.0.

2.1 Meningkatkan kesadaran masyarakat tentang kebersihan lingkungan sehingga dapat membantu program organisasi CTI dalam proses pelestarian terumbu karang.

2.2 Meningkatkan kesadaran masyarakat tentang kebersihan lingkungan, sehingga mendorong ekowisata bahari Kota Manado dapat bersaing dalam menghadapi era revolusi industri

$\begin{array}{llllllll}4 & 4 & 3 & 3 & 3 & 4 & 3 & 24 \\ (\mathrm{VII})\end{array}$

$\begin{array}{llllllll}4 & 2 & 3 & 3 & 2 & 2 & 3 & 19\end{array}$

$\begin{array}{llllllll}4 & 2 & 4 & 4 & 3 & 4 & 3 & 24 \\ (\text { IV) }\end{array}$ 4.0.

\section{STRATEGI (WT)}

1.1 Melaksanakan penegakan hukum terhadap wisatawan yang melanggar peraturan dalam rangka meminimalisir kerusakan lingkungan ekowisata bahari Kota Manado

1.2 Melaksanakan penegakan hukum terhadap pengelolaan sampah di $\begin{array}{llllllll}4 & 4 & 4 & 4 & 4 & 3 & 3 & 26 \\ \text { (II) }\end{array}$ darat maupun di laut dalam rangka pembangunan ekowisata bahari yang berkelanjutan.

2.1 Meningkatkan kesadaran Masyarakat tentang kebersihan

ota




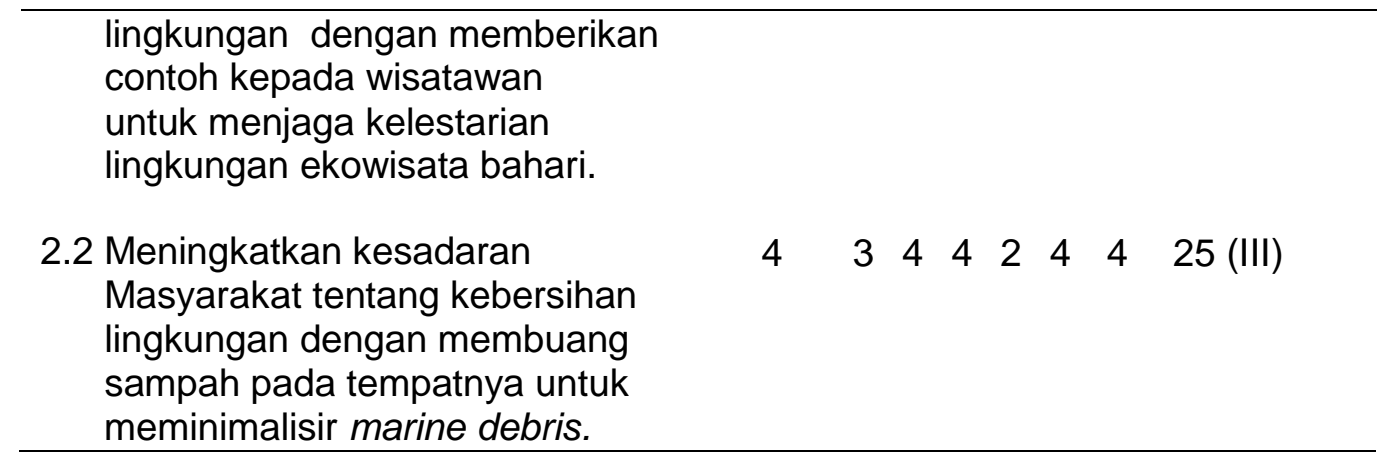

\section{Faktor-Faktor Kunci Keberhasilan}

Dari 7 faktor-faktor kunci keberhasilan dalam Tabel 5, maka dirumuskan secara sederhana menjadi 4 strategi prioritas dalam rangka pengelolaan ekowisata bahari Kota Manado di era revolusi industri 4.0 berbasisi digital, sebagai berikut :

1) Meningkatkan penegakan hukum di bidang ekowisata bahari, pengelolaan sampah di darat maupun di laut,

2) Menyadarkan masyarakat tentang kebersihan lingkungan baik di daratan maupun di lautan,

3) Memberdayakan sumber daya keanekaragaman hayati terumbu karang, padang lamun dan mangrove kawasan TNB untuk pengembangan ekowisata bahari melalui aplikasi digital, dan

4) Mengelola dan mengembangkan resort, tempat-tempat wisata kuliner pantai, titik-titik penyelaman, dan pelabuhan pariwisata.

\section{KESIMPULAN}

Dalam rangka implementasi revolusi industri 4.0 saat ini, maka melalui 4 rumusan strategi prioritas yang diperoleh merekomendasikan bahwa setiap pengelola atau pemangku kepentingan industri ekowisata bahari di Kota Manado sudah seharusnya merubah sistem pengelolaan yang ada ke arah berbasis digital dengan cara membuat aplikasi khusus pengelolaan ekowisata bahari.

\section{DAFTAR PUSTAKA}

Bagindo, M., Sanim, B., dan Saptono I. T. 2016. Model Bisnis Ekowisata di Taman Nasional Laut Bunaken dengan Pendekatan Business Model Canvas. Manajemen IKM. Vol. 11. No. 1. Bogor. 9 hal.

Bahagia, Y., Paruntu, C. P., Darwisito, S. 2016. Deskripsi SWOT, KAFI dan KAFE Terhadap Hasil Penelitian di Program Studi IImu Kelautan Fakultas Perikanan dan IImu Kelautan UNSRAT. Jurnal Pesisir dan Laut Tropis. Vol. 2 No. 1. Manado. 9 hal.

Paruntu, C.P., dan Rumengan, A.T. 2018. Panduan Praktis Analisis Kebijakan Kelautan dan Perikanan. Manado. Unsrat Press. 166 hal.

Peraturan Menteri dalam Negeri nomor 33 tahun 2009 tentang pedoman pengembangan ekowisata di daerah. Kementerian Dalam Negeri. Jakarta. 8 hal.

Posundu, R. S. A., Kepel, R. C., Mandagi, S. V., Kalalo, F. P., Paruntu, C. P., Mingkid, W. M., Boneka, F. B. 2019. Kajian Strategi Pembangunan Zona Fasilitas Umum Penunjang Pariwisata di Teluk Manado. Jurnal Ilmiah Platax. Vol. 7. No, 1. Manado. 15 hal. 
Rangkuti, F. 2006. Analisis SWOT Teknik Membedah Kasus Bisnis. PT. Gramedia Pustaka Utama. Jakarta. 200 hal.

Rangkuti, F. 2015. Personal SWOT Analisis Peluang di Balik Setiap Kesulitan. PT. Gramedia Pustaka Utama, Jakarta. 223 hal.

Satya, V. E. 2018. Strategi Indonesia Menghadapi Industri 4.0. Pusat Penelitian Badan Keahlian DPR RI. Vol. 10. No. 9. Jakarta. Hal. 19-24.

Sutanto, Y., Suyanto, M., dan Fatta, H. A. 2013. Analisis Inovasi Nilai Sebagai Perancangan Strategi Perusahaan Pada STMIK AMIKOM Yogyakarta. Jurnal Teknologi Informasi. Vol. Vii No. 22. Yogyakarta. $18 \mathrm{Hal}$. 